\title{
Can we personally influence the future with our present resources?
}

\author{
C. Gros ${ }^{1}$, K. Hamacher ${ }^{2}$, W. Meyer ${ }^{3}$
}

\begin{abstract}
Influencing the future of mankind for the better, supporting sustainable development and realizing ambitious plans as the colonization of outer space? But how? In this paper we will differentiate two distinct approaches: (I) immediate action/projects - most NGOs follow this avenue and (II) long-term growth within an evolvable and improvable organization to accumulate both financial resources and methodical, scientific and procedural knowledge to support the goals.

We explain how the initiative 'Future $25^{\prime}$ tries to develop a foundation whose goal is to maintain a platform for the second approach. The long-term perspective requires special organizational prerequisites to support a stable structure and by that the desired long-term growth. The direct member participation results as a possibility in contrast to most foundations that are governed by a small group of people. Our foundation will be heavily based on the utilization of the Internet to realize what we will introduce as maximum participation. We show how current sociological research prompts for concepts such as monitoring and evaluation to support the stability of the organization and facilitate new developments and changes within the foundation.

We discuss organizationial, sociological, legal, technological and financial issues.
\end{abstract}

\section{Avenues to the future}

We don't have presently, and this is one thing we are definitely sure about, the capabilities of the psycho-historians of Isaac Asimov's Foundation trilogy to predict our future. Uncertainty about consequences is the fate of all our decisions and we suppose that our own personal action can not significantly change the way things go. Although we are struggling for the capacities to foresee our future since the beginning of our history, we are still lacking this capability and it seems to be improbable that humanity will ever acquire it.

However, our interests are not only limited to the nearby future of our personal lives and of the respective societies we are living in. We are also curious what the long-term future will harbor for mankind and if we, as ordinary individuals living today, can do something about it. Confronted with horrible scenarios on world wide climate changes and other catastrophes (e.g. Rees, 2003) that probably will be the outcome of our deeds and those of our predecessors, responsibility for the future and sustainable action with respect for our descendants seems to be more important than ever. So this is the rational of this paper: what can we do to influence the long-term future or, more precisely, what must be done to ensure (positive) long-term consequences for our action?

Thinking a little while on the subject, we may come-up with two, fundamentally different, avenues of approach:

\section{(I) First avenue to the future: Act now.}

We try to change the present and our immediate future in such a way, that the consequences of our actions ripple down in time and history, influencing in a desired way events yet to happen in the far

\footnotetext{
1 Physics Department, University of the Saarland, D-66123 Saarbrücken, Germany, http://www.uni-saarland.de/gros.

2 Center for Theoretical Biological Physics, University of California, San Diego, 9500 Gilman Drive, MC0374, La Jolla, CA 92093, USA, http://www.kay-hamacher.de.

3 Center for Evaluation (CEval), University of the Saarland, D-66123 Saarbrücken, Germany.

4 http://www.future25.org
} 
future. In a more defensive form, this is the approach of sustainable development, defined as a development 'that meets the needs of the present without compromising the ability of future generations to meet their own needs' (World Commission 1987: 8) in the famous report "Our Common Future" of the UN World Commission on Environment and Development. This approach is very intuitive: Change the present for the better now, or at least trying to do so, hoping for a positive outlook. Sustainable action, in this sense, means to make decisions that produce longlasting positive outcomes and being able to avoid negative side-effects continuously. Unfortunately, we are facing two difficulties with this approach.

The first obstacle is our above mentioned in-capability to actually predict the long-term future. We are not only missing data and knowledge about the complex structures and relationships of the world we are going to live in future times. Moreover, we have to predict unpredictable events and have to implement solutions for problems we do not even have a clue whether they will arise or not and, if ever, at which time they will occur. The longer the time period in discussion, the more probable we are facing a lack of information on the problems that have to be solved. Furthermore, not only our knowledge decreases but also the difficulties for further generations to ascribe measured impacts to our action will increase. Even Asimov's Foundation gets in some trouble on this point: while Hari Seldon (the Founder) could not precisely calculate all future developments, the discussion within the Foundation society raise, whether he had been able to foresee the actual difficulties or not.

The second problem lies in the limited resources we dispose of, as simple individuals or as a small group of engaged citizens (the smaller the group the weaker is in general the assumable impact of their action). One may object that there are many individuals who did actually change the course of history alone for the better or the worse and that it is nowadays possible, in principle, for ordinary citizens to achieve positions, like the American presidency, which allows to exert personally and directly an enormous political and economical influence. However, even if we assume this being correct in an open society, it is exceedingly difficult to achieve such an influential position without the devotion of a lifetime. Even then, when devoting all ones energies and time to achieve an influential position, any single person has not more than a tiny chance to actually achieve this goal. It may even be incompatible to devote energies for the advancement to such a position and to work for long-term changes simultaneously.

However, history teaches us that even people who did not have any political or economical power are able to influence the course of our development significantly. Sometimes individual action can start an epidemic spreading across huge regions and time periods (for some popular examples see: Gladwell 2000). Unfortunately, the impact of such kind of social diffusion processes remains unpredictable especially as long as there is no continuous monitoring and routing of the process towards the requested direction. We need sustainable impacts not only on the first dimension of sustainability (implementing sustaining solutions) but we also need social institutions for sustaining production of solutions (fourth dimension of sustainability, see figure 1). Even Isaac Asimov's Founder Hari Seldon implemented a second foundation for steering the development.

\section{(II) Second avenue to the future: Act then.}

As a consequence, it seems not to be sufficient if we are acting now to influence the course of future events directly even if our actions have some sustainable positive impacts for our descendants. Future events have to be influenced precisely at the time when they will happen (or when they can be prevented or supported) possibly long after we ceased our own individual activities on earth. As far as we are not able to predict the future, we will need to motivate other people now and then in the future, to carry out, and to carry on, this endeavor. Furthermore, we have to hand our ideas how to steer the future (e.g. the concept of sustainable development) over 
from generation to generation, or give basic guidelines how to evolve these concepts to a changing socio-cultural environment.

\begin{tabular}{|c|c|c|c|}
\hline \multirow{5}{*}{$\begin{array}{l}\text { Are there any new } \\
\text { Social institutions } \\
\text { implemented within }\end{array}$} & \multicolumn{3}{|c|}{ Is there any potential for innovations implemented? } \\
\hline & & No & Yes \\
\hline & No & Sustaining Solutions & On-going solution \\
\hline & & (Dimension I) & development \\
\hline & & & (Dimension II) \\
\hline & Yes & $\begin{array}{l}\text { Sustaining Institutions } \\
\text { (Dimension III) }\end{array}$ & $\begin{array}{l}\text { On-going institutional } \\
\text { development } \\
\text { (Dimension IV) }\end{array}$ \\
\hline
\end{tabular}

Figure 1: Four dimensions of Sustainable Impacts..$^{5}$

(Basing on Meyer (2002) and Stockmann (1997), modified.)

While our life-time is strongly limited to a short period, our ideas may be able to last for longer. A successful historical example from the occident is Jesus Christ, whose speeches and deeds in a very small and politically marginalized country spread throughout the whole world and survived more than two thousand years, impressing millions of people in the course of history. Similar examples of sustaining ideas can be found in other religions as well as in arts, politics and sciences.

These processes had been guided for the better and the worse by social institutions throughout the centuries. Durable social organizations had been implemented to protect the idea against challenges, to support the diffusion of the idea, to adopt it to new social developments and to decide between different interpretations of the idea. Therefore, social institutionalization of an idea is at least as important as the idea itself for its survival.

If we want to influence the future then, we have to use our present resources for building up sustainable social institutions. The objective of these institutions have to be the empowerment of future generations to overcome the troubles we are not able to foresee (or to battle successfully) and to give them the capacities and resources for doing that successfully. We will point out in this article that a suitable organized non-profit organization, growing continuously over time, could do the job. Our main task is to ensure this organization for developing an ever growing amount of resources (in form of both money and knowledge).

This approach then solves immediately the predictability problem. We do not need to be psychohistorians in order to discern possible important issues for the future development of humanity, let's say, for the next few centuries. Our descendents will then be there to ascertain the specific issues to be dealt with, hopefully with vast resources at their disposal. This second approach also solves, at least partially, the problem of the limited amounts of resources available to us individually, since long-term growth will lead eventually to massive financial resources, even when starting with an initially modest endowment. Regarding the concept of sustainability, the capital stock will be left untouched (and is probably growing if more and more people invest in the fund) while interest proceeds can be used for activities. Depending on growth and interest rates, the organizations ability to finance human actions will increase over the centuries.

Having this idea to influence the future in mind, some very important questions have to be answered:

- What are the objectives of this organization? Which future tasks should be handled in

\footnotetext{
${ }^{5}$ Examples: (Dimension I) Books presenting new ideas and proposals. (Dimension II) Scientific research published in journals. (Dimension III) Social institutions with a fixed program (e.g. a company). (Dimension IV) Social institutions capable of autonomous development (e.g. the economy).
} 
which way?

- What kind of social measures can be used to ensure that the resources of the organization will be durably used for the goals attended by us? How can we prevent individual abuse for personal benefits?

- How can we permanently control the impact processes produced by the activities of this organization and guarantee that the development is directed towards the intended goals?

\section{The objectives: 'Big questions' on the future of mankind}

The first question to be answered by building up a sustaining organization is: what are the objectives of such an organization? For the purpose of this article we consider now the fundamental motivations of the nascent initiative 'Future 25'. Considering the 'big picture', the future of live and mankind on earth and in the universe, we may formulate some basic, partially related, issues:

- Will large-scale ecological habitats survive human activities on earth? In the long-run?

- Will humanity ever support large-scale space exploration and support the development of life on other planets?

Nobody can, of course, give definite answers to above questions, or, in this respect, to any other 'big question'. In fact, this is one of the reasons that they are called 'big questions'. Some may even argue that those questions are not important because they are too big and an answer is almost impossible to find from our recent perspective. Others may criticize these questions from a moral point of view and refuse them as aspiring goals or dispute them on an ethical basis. We may, however, consider general socio-economical and structural conditions needed to resolve above issues positively without discussing whether these questions are really the right topics for a sustaining organization or not. Here, we concentrate instead on the question of why non-profit organizations are needed to handle the issues above.

If we leave these tasks to governments and governmental agencies then the answer to both big questions is probably no. The primary concern of democratic governments is to satisfy the needs of their people here and now. Only secondary considerations, if at all, will lead governments to decisions having a positive and lasting impact in distant future. Governments are accountable only to their living electorate, not to their descendents. To keep the electorate in a spirit to demand sustainability over long periods would still need social structures to hold up these ideals and to achieve a majority for these goals. Non-democratic governments are even not feeling responsible for their people at all.

While the political system seems to be unsuitable to contribute to the big questions of humanity, some may set some hope in the market forces of the economical system. Unfortunately, market failures limit the regulating power of market forces: the function of market have to be guaranteed by legal systems that assure fair trade and correct price fixing. To realize sustainable development one has to assure the precise recognition of distant future costs which have to be taken into account and weighted with present benefits. What, if all external cost would be 'internalized', would be the real oil price? Moreover, striving for individual benefits and not protecting common goods are the driving forces of the market system.

Most recently, non-profit oriented civil-society organizations understand themselves as gatekeepers of common goods. Their ability in mobilizing people and organizing effective collective actions is an important threat for those who want to abuse common goods for their own profit. While politicians may be dependent on commercial interests (e.g. for financing their election campaign), the voluntary participants of civil-society organizations are more difficult to control. Unfortunately, civil-society organizations itself are dependent on the deliberate decision of their 
members to engage for common issues. In general, people are concerned by actual problems and not by the distant future.

Nevertheless, there are many people who are interested in future topics. The avenue to the future, when applied to problems afflicting us today, is shared by a wide range of non-governmental associations and non-profit foundations. All contributing in their ways to the progress of our civil society, mostly pursuing the first avenue to the future. We believe that the civil society would benefit qualitatively if one or more non-profit associations, dedicated to the second approach to the future, would complement, in a kind of symbiosis of different approaches, the estimable array of private associations and foundations.

\section{The organization: challenges and principles}

The establishment of a globally active, non-profit organization, dedicated to long-term external and internal growth for the benefit of our descendents presents a formidable challenge. This organization would have to grow financially and membership wise over very long periods. The annual growth rates would not need to be large, internal financial growth rates of 3-4 percent are sufficient and attainable. This organization would need an internal structure allowing to hand down over many generations the ideas of the founders, our ideas for the future of humanity. Basic economics tells us, that the financial resources of this foundation would grow, within a few centuries to such massive size, that our descendents would then have the means, by using them wisely, to actually change, in certain aspects, the course of history, for example by promoting the lasting and successful expansion of mankind to outer space.

This organization would not be initially inactive. Immediately it would start to finance regularly projects as any other non-profit foundation does it nowadays. But at a reduced rate, in order to retain enough money for internal growth. Considering the respective national laws for non-profit organizations we find that this strategy is possible for a German non-profit foundation, but not for an American trust, as we will discuss further below.

When successful, this organization would contribute in quite a few different ways to the advancement of civil society, besides financing large- and larger-scale projects with the passing of time. It would need to evolve into a test-bed for applied sociology and political sciences.

\section{Legal aspects}

National laws regulate the financial activities of non-profit associations. A charity in the US has to spend on the average 5 per cent of the fair value of its endowment every year, limiting strongly its growth potential. A nonprofit foundation in Germany has to spend on projects the majority of the annual yields, like dividends and interests, the actual endowment is protected and cannot be used for charitable or other means. With a suitable investment strategy, one possibility is to invest the endowment predominantly in stocks, a long-term growth of the endowment can be achieved.

German law permits two kinds of tax-deducible donations to a non-profit foundation: the normal donation to be used for the charitable activity and donations towards the endowment, increasing it in size. This venue of external financial growth is especially important in the starting phase of a nascent non-profit foundation. It is therefore natural for a growth-oriented foundation to identify co-founders, i.e. everybody donating a certain amount towards the endowment, with members.

\section{The organizational structure}


As of today, we find two dominant generic types of organizational structures for non-governmental bodies: with and without internal democracy. Organizations without internal democracy typically have self-electing governing organs, for instance a board of directors: When one board-member leaves, the remaining ones co-opt a new member. According to national laws and basic-democratic ideals the vast majority of civil-society organizations are democratically ordered with members that elect their board for a defined period. In bigger organizations the election process is divided in several different levels and the members of the lower level elect delegates for the higher level. Nevertheless, strong democratic principles are established in nearly all cases.

As far as clubs and other registered associations are acting principally for the benefit of their members, the internal democracy is strongly limited to members and membership is voluntary giving each member a voice (the right to get his or her interests represented) and an exit (the freedom to leave the organization if he or she wants to) opinion (see Hirschman 1970). Therefore, the main problem of each civil-society organization is to stabilize membership and to continuously mobilize them for common objectives.

\section{Stable internal democracy}

Self-electing organs constitute very efficient governing organs for organizations with a well specified aim and purpose. Most charities, to give an example, spend the available money in very regular ways every years within recurring programs. Major decisions, like the discontinuation of an existing program, are only rarely up to decision by the governing organ. The most important work is carried out on a daily basis by the administrative staff.

An association dedicated to the long-term perspective cannot have, on the other hand, a fixed a priori program. Important decisions will be needed along its way into the future. A self-election organ is not suited to carry out this mission. Its human resources are, by definition, limited and constant and independent control of its actions are difficult to achieve. The association dedicated to the second approach to the future therefore needs a properly thought-out democratic structure.

To find a suitable internal democratic structure for a globally active organization with a long-time horizon might appear, on the first sight, a trivial task, since so many democratically organized associations already do exists. To guarantee from the outset the stability of an association over very long time-spans is, however, a challenge and we can only discuss now some of the most important and difficult points.

\section{Member participation}

Private associations and non-governmental organizations enter frequently, especially with growing size, a stage with a dramatic reduction in the effectiveness of the internal democratic decisionmaking and participation processes. Quasi oligarchic informal internal networks may form and effectively exclude the other members from the decision-making process. Or the internal communications channels may be insufficient to keep up with growing demand (Meyer 2004). A tendency for larger organization to develop indirect systems of democratic participation, stemming from limited pre-Internet communication channels, with delegates speaking for local subunits or internal interest groups, also harbors the risk of reducing the effectiveness of democratic communication. On the other hand, the request for effective communication increases by the number of people involved in decision processes and professional communication measures and management is definitely needed. Therefore, a foundation for the future has to implement professional communicational management and to optimize them with respect to the communicational development within the organization. 
This permanent development process draws support, beside other, from current economical, sociological and psychological research, confirming the positive influence of participation possibilities on the satisfaction of the members of an organization. This is an all-important basis prerequisite for a non-profit association, which is dependent on the voluntary participation of active and motivated members. The term 'procedural utility' has been coined in economics to describe the satisfaction somebody receives from undertaking an action (procedure), irrespectively from the outcome. Studies have shown that procedural utility is increased not only by the actual participation processes, but already from the conceived possibility to participate, even if the actor chooses not to make use of this possibility (Frey and Stutzer, 2002).

The rise of the Internet has opened new communication and participation channels for non-profit organization yet unused in many traditional associations. A key example in this respect is the direct involvement of all members of a non-profit foundation in selecting the projects to be financed yearly by the proceedings of the endowment. We are not aware presently, of any foundation allowing for such a direct participation of its members. The vast majority of non-profit foundations do not accept members at all; they are controlled by self-electing execution organs installed by the original founders. And the small fraction of foundation allowing real members do mostly not yet exploit fully the power of Internet participation.

\section{Monitoring and Evaluation}

It is unrealistic to assume that it is possible to conceive out from the start already the optimal structure for an association, optimal for stability, internal and external long-term growth. What is possible though, is to formulate basic guiding principles. The foundation 'Future 25' would try to continuously improve its own internal organization, communication channels and participation possibilities. It would therefore present a platform for experiments in applied sociology and political sciences. Proper evaluation principles, a functional continuously used impact monitoring system, and regular critical documentation of the effectiveness and efficiency of its own structure are therefore mandatory and might be beneficial for other non-profit organization aiming to improve their own organizational structures. Yet, most civil-society organizations are very poor in these aspects and they do not, in general, have any kind of monitoring and evaluation system implemented.

Effective and continuous internal evaluation, combined with a thorough open internal and external information policy, should help to detect appropriate warning signals. Comprehensive free availability of information would imply, to give an example, the publication of all financial details and of all meeting-protocols on the home-page of the foundation. It should also allow the free and effective discussion of the evaluation results and such stimulate counter-actions. Future 25 will therefore serve, if successful, as a test-bed for various possibilities of internal evaluation with the aim of optimizing both the evaluation-tools themselves and the growth potential of the association.

\section{Principles for long-term stability and growth}

Following the discussion above, we can now formulate three basic principles helping to support a stable and evolving internal democracy:

(a) Optimal participation possibilities for all members.

(b) A comprehensive and fully open flow of information.

(c) Continuous internal and external evaluation.

We believe that these three guiding-principles provide a basis for long-term stability and long-term 
growth, and that other requirements follow from here. The need for an internal balance-of-powers, to give an example, results from (a) and from the external requirement that, by law, any registered foundation needs to nominate legal representatives, e.g. in the form of a board of directors.

\section{The role of the Internet}

The utilization of the Internet for direct communication between all members, sub-groups and administrative contacts is a cornerstone of our plans for three reasons:

- The Internet is nowadays a world-wide communication tool, faster and more reliable for communication between different regions of the world than any other system and therefore most suited for a global organization.

- The costs are reduced in comparison to paper-based mailing and face-to-face meetings involving substantial traveling.

- The Internet is up to now our only way to achieve the goal of direct member participation and the possibility of systematic organizational evolution.

While the first two points are obvious the third needs some further elaboration. There are several aspects where an Internet-based communications platform is useful. ${ }^{6}$ As discussed above, we estimate direct participation and the facilitation of procedural utility to be crucial for establishing a growing and internally stable organization. One of several approaches to discuss intraorganisatonial 'hot topics' and to propose new ideas for further developments is the Open-SpaceConcept (Owen 1997). The concept itself has been used up to now only for face-to-face meetings in real places, in our case people will come together virtually. In an open-space meeting there are no speakers or round-tables as in traditional conferences, people establish an agenda with priorities on their own. It would be impractical to have several dozens up to several thousands of Future 25members invited to some place. In addition to the large organizational and travelling costs we would build up barriers for direct participation, since many members would not be able to participate in-persona due to other constraints (business, family, etc.). Virtual open-space meetings would also allow for longer-lasting discussions, increasing the possible success rate, i.e. that proposals resulting from these discussions will be eventually implemented. Therefore this approach makes it also feasible to discuss topics of highest importance such as consequences from evaluations and monitoring activities in length with an ending call for voting; giving every member the chance to review the exchange in the electronic archive of such a meeting.

The concept of an Internet-based open-space conference discussed above is an example of structured opinion formation. Effective intra-organizational communication needs also informal channels. Every member of Future 25 would be empowered to invoke a discussion forum on his or her own for some topic he wants to discuss, creating a marketplace for ideas. It is important that important discussion forums have a resonance beyond the people actually participating in it. A forum in which a topic is discussed that many participants feel to be important for Future 25 needs to receive attention. For this purpose we have developed the concept of 'results-oriented discussionforums'?.

Direct communication by a message system or by 'normal' e-mails from member-to-member, will lead to personal networks of members. These networks of personal contacts, trust and common interests are best described by the small-world-phenomena (Watts 1998, Albert 2002) that gives raise to the hope that the open participation opportunity leads to personal contacts accelerated by the high 'connectivity' and short 'distances' between people in small-world-networks, accelerating

\footnotetext{
${ }^{6}$ Please see also for the concept of 'Structured opinion formation via Internet': http://www.future25.org/structure.html\#opinionFormation

${ }^{7}$ Please see: http://www.future25.org/structure.html\#discussionForums
} 
in the end the advance of the foundation on its own. To take psychological effects into account, Future 25 will provide every member the storage to save a small 'homepage' to give everybody the chance to look at a photograph or get informed about one's respective hobbies and such.

\section{Technological prerequisites}

The necessary infrastructure in terms of computers and Internet-connections is small, affordable and the technology is already developed. Beside regular newsletters and an official web-site which should not only inform members about current topics but also non-members about the philosophy, activities of Future 25 and about participation opportunities we propose the use of the Internet for internal democracy and participation activities.

For voting and other communications that is sensitive, we plan to use an established, well-known and by several official bodies approved cryptographic system a-la GnuPG (GPG). It will not only enable the private exchange between people but also the authentication in voting procedures or discussions. A public key for the main administrative account will be certified by a central instance and used to sign further cryptographic keys for administration that then will certify member keys.

The Foundation Future 25 is forward looking: Awareness of the future implies consciousness of the past and Future 25 will therefore maintain a complete archive system. A Document Management System would further increase the effectiveness of this archive. It will allow to substantiate the past development and to document the outcome of organizational reforms and experiments.

\section{Conclusions}

We have turned around the intuitive approach

'We cannot easily change the course of future events, but we may hope to predict them'

and asked the question:

'If we cannot foresee the long-term future, can we do something about it?'

Our answer is affirmative and we have proposed here a set of fundamental principles for achieving this goal:

(A) Influence through long-term growth of resources.

(B) Socialization of the guiding idea.

We believe, in particular, that a small group of determined citizens without political aspirations and, initially, with only modest financial resources may take actions that will eventually change the outcome of events and developments yet to take place in the far future, somewhat in the spirit of a quote attributed to the anthropologist Margaret Mead:

"Never doubt that a thoughtful group of committed citizens can change the world - indeed it's the only thing that ever has."

Margaret Mead's statement relates, however, to movements able to mobilize the society with their ideas and actions. For this to happen a new idea needs to spread and to diffuse and this is possible only if the circumstances do allow this to happen - if the time is ripe for a new concept. What we propose here is much more modest in nature. There is no need to stir-up the whole society; this would be a titanic task. Here we suggest that a historical window of opportunity has opened in the last years, allowing to establish a lasting foundation in order to advance our solidarity with future 
generations. Considering the steady rise in future-related activities, the growing concerns about our environment and sustainability, the growing possibilities to communicate and to organize effectively and globally via the Internet, we see this window of opportunity presently wide open. The nascent initiative Future 25 is, in its very nature, open for participation, like the open-source movement. We extend a friendly invitation for collaborations.

\section{References}

Albert, Reka and Albert-Laszlo Barabasi: 'Statistical mechanics of complex networks', Rev. Mod. Phys., 74, 47-97 (2000).

Frey, Bruno S. and Stutzer, Alois: 'Beyond Outcomes: Measuring Procedural Utility' (April 29, 2002). Berkeley Olin Program in Law and Economics, Working Paper Series. Paper 63. http://repositories.cdlib.org/blewp/art63

Gladwell, Malcom: 'The Tipping Point. How Little Things Can Make a Big Difference', Little Brown \& Co. (2000).

GPG: http://www.gnupg.de/

Hirschman, Albert O.: 'Exit, Voice and Loyality. Responses to Decline in Firms, Organizations, and States', Cambridge: Harvard University Press (1970).

Meyer, Wolfgang: 'Sociological Theory and Evaluation Research. An Application and its Usability for Evaluating Sustainable Development', Saarbrücken: CEval-Working-Paper No. 6 (2002). http://www.ceval.de

Meyer, Wolfgang: Regulation, Responsibility and Representation . Inter-organisational coordination and its relationship to intra-organisatonial communication', (forthcoming paper; 2004).

Owen, Harrison: ‘Open Space Technology: A User's Guide’, Berrett-Koehler (1997).

Rees, Martin: 'Our final century’, W. Heinemann, London (2003).

Stockmann, Reinhard: 'The Sustainability of Development Cooperation', Baden-Baden: Nomos (1997).

Watts, Duncan J. and Steven H. Strogatz: 'Collective dynamics of small-world networks', Nature, 393, 440-442 (1998).

World Commission on Environment and Development; 'Our Common Future', New York: Oxford University Press (1987). 